\title{
Structure-based Optimization and Derivatization of 2-Substituted Quinolone-based non-Nucleoside HCV NS5B Inhibitors with Submicromolar Cellular Replicon Potency
}

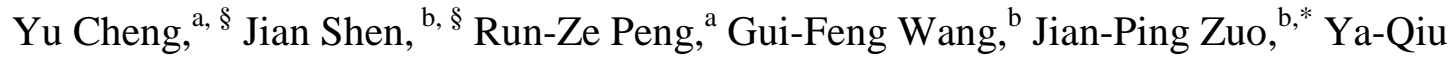
Long $^{\mathrm{a}, *}$

${ }^{a}$ CAS Key Laboratory of Receptor Research, ${ }^{b}$ State Key Laboratory of Drug Research, Shanghai Institute of Materia Medica, Chinese Academy of Sciences, Shanghai 201203 , China

\begin{abstract}
$\mathrm{HCV}$ NS5B polymerase is an attractive and validated target for anti-HCV therapy. Starting from our previously identified 2-aryl quinolones as novel non-nucleoside NS5B polymerase inhibitors, structure-based optimization furnished 2-alkyl-N-benzyl quinolones with improved antiviral potency by employing privileged fragment hybridization strategy. The $N$-(4-chlorobenzyl)-2-(methoxymethyl)quinolone derivative $\mathbf{5 f}$ proved to be the best compound of this series, exhibiting a selective sub-micromolar antiviral effect $\left(\mathrm{EC}_{50}=0.4 \mu \mathrm{M}, \mathrm{SI}=10.8\right)$ in Huh7.5.1 cells carrying a HCV genotype 2a. Considering the undesirable pharmacokinetic property of the highly substituted quinolones, a novel chemotype of 1,6-naphthyridine-4,5-diones were evolved via scaffold hopping, affording brand new structure HCV inhibitors with compound $\mathbf{6 h}\left(\mathrm{EC}_{50}(\mathrm{gt} 2 \mathrm{a})=2.5 \mu \mathrm{M}, \mathrm{SI}=7.2\right)$ as a promising hit. Molecular modeling studies suggest that both of 2-alkyl quinolones and 1,6-naphthyridine-4,5-diones function as HCV NS5B thumb pocket II inhibitors.
\end{abstract}

Keywords:

HCV NS5B polymerase, 2-alkyl quinolone, 1,6-naphthyridine-4,5-dione, non-nucleoside inhibitor, direct acting antiviral, allosteric site

\footnotetext{
${ }^{*}$ Corresponding authors. Tel \& Fax: 86-21-50806876; Email: yqlong@ simm.ac.cn (Y.-Q. Long), jpzuo@simm.ac.cn (J.-P. Zuo).

${ }^{\S}$ These authors contributed to this work equally.
} 
As a leading cause for liver fibrosis, cirrhosis, and hepatocellular carcinoma, ${ }^{1}$ chronic hepatitis $\mathrm{C}$ virus (HCV) infection has been estimated to affect about 160 million people worldwide and causes approximately 500,000 deaths annually from HCV-related liver diseases. ${ }^{2,3}$ For a long span of time, the standard of care (SOC) for $\mathrm{HCV}$ treatment has been based on a combination of pegylated interferon $\alpha$ (pegIFN- $\alpha)$ and ribavirin (RBV), which cured approximately $50 \%$ of treated patients after weekly injections for 12 months, but sometimes caused severe adverse reactions with low sustained viral responses (SVR) against HCV genotype 1 strains. ${ }^{4,5}$ Direct-acting antiviral agents (DAAs), an interferon-free treatment selectively targeting essential proteins in $\mathrm{HCV}$ life cycle, ${ }^{6}$ were first validated as an effective approach for $\mathrm{HCV}$ therapy by the market approval of NS3/4A protease inhibitors (telaprevir ${ }^{7}$ and boceprevir $^{8}$ ) in 2011. The past five years have witnessed a vast number of DAAs including NS4B inhibitors, ${ }^{9}$ NS5B inhibitor ${ }^{10}$ ( sofosbuvir $^{11}$ and dasabuvir ${ }^{12}$ ) and NS5A inhibitors (ledipasvir ${ }^{13}$ and ombitasvir ${ }^{14}$ ). The multiple combination of theses DAAs have achieved high SVR in clinical trials. ${ }^{15}$ However, intense drug discovery efforts are still urgently needed because consecutive interaction of these agents with the highly mutational virus leads to the emergence of drug resistance.

HCV non-structural protein 5b (NS5B), a RNA dependent RNA polymerase, plays a critical role in HCV genome replication. ${ }^{16}$ The absence of a counterpart of this enzyme in human body makes it an attractive therapeutic target. NS5B inhibitors are classified into nucleoside inhibitors (NIs) that bind to the active site and non-nucleoside inhibitors (NNIs) that bind to the allosteric sites. The right-hand-like structure of NS5B polymerase can be morphologically divided into "thumb", "palm", and "finger" domains. ${ }^{17}$ Until recently, five allosteric sites have been identified for NS5B polymerase and two of them reside in the thumb domain (thumb site I, TSI and thumb site II, TSII). ${ }^{18}$ A broad range of TSII inhibitors emerged in the last few years, ${ }^{10}$ but none of them has been approved for clinical use. Therefore, this underexploited area offers great opportunities for developing new antivirals with distinct mechanism to treat drug-resistant $\mathrm{HCV}$ infection. 
Our research group has been working on the drug-like privileged scaffolds to generate novel chemotherapeutic agents, especially interested in the construction and biological application of quinolone scaffold. ${ }^{19-22}$ The quinolones have been reported to be the NS5B TSII inhibitors (Fig 1, compounds 1-3), ${ }^{23-25}$ as confirmed by the cocrystal structure of ligand 2 bound to NS5B polymerase (PDB code $3 \mathrm{PHE}$ ). ${ }^{23}$ Based on the complex structure, for the first time we introduced a hydrophobic group at C-2 position on the quinolone core and identified a new series of 2-aryl-quinolones to inhibit HCV replication in subgenomic replicon system at micromolar concentrations, with derivative 4 showing the best biological profile $\left(\mathrm{EC}_{50}\right.$ (replicon, gt $\left.2 \mathrm{a}\right)=2.02 \mu \mathrm{M}$; $\left.\mathrm{CC}_{50}=13.2 \mu \mathrm{M}\right) .{ }^{22}$ Herein we report our further optimization effort to improve the anti-HCV potency of the 2-arylquinolone series based on the binding mode of the quinolone NS5B inhibitor, producing $N$-benzyl-2-(methoxymethyl)quinolone derivatives with sub-micromolar anti-HCV potency in genotype 2a replicon and novel chemotype HCV inhibitors bearing 1,6-naphthyridine -4,5(1H,6H)-dione scaffold.<smiles>CN1CCN(c2cc3c(cc2F)c(=O)c(C(=O)OCc2ccc(Cl)cc2)cn3Cc2ccc(Cl)cc2)CC1</smiles><smiles>CN1CCN(c2cc3c(cc2F)c(=O)c(C(=O)OCc2ccc(Cl)cc2)cn3Cc2ccc(S(C)(=O)=O)cc2)CC1</smiles>

$$
\begin{aligned}
\mathrm{HCV} \mathrm{EC} \mathrm{E}_{50}(\mathrm{gt} 1 \mathrm{a}) & =0.41 \mu \mathrm{M} \\
\mathrm{EC}_{50}(\mathrm{gt} 1 \mathrm{~b}) & =0.12 \mu \mathrm{M}
\end{aligned} \quad \mathrm{HCV} \mathrm{IC}_{50}(\mathrm{gt} 1 \mathrm{~b})=0.016 \mu \mathrm{M}
$$<smiles>[R14]O[R20](=O)O[C@H]1CC1n1c(-c2ccc(F)cc2)c(C(=O)OCc2ccc(Cl)cc2)c(=O)c2cc(F)c(N3CCN(C)CC3)c(F)c21</smiles>

Fig 1. Representative quinolone-based NS5B polymerase inhibitors

Careful examination of the co-crystal structure of quinolone 2 bound to the polymerase TSII site (PDB code: $3 \mathrm{PHE})^{23}$ and the structural superimposition between 
$\mathbf{2}$ and $\mathbf{4}$ suggested a preference of a bulky aromatic hydrophobic group at N-1 position and an additional small hydrophobic group at C-2 position to fully occupy the deep hydrophobic pocket lined by Leu419, Va1485, Ala486, Leu489, Leu497 and Met 423, and gain additional interaction with the surface cleft delineated by Leu419 and Leu497. Furthermore, we assume that a proper functional group in C-2 substituent might form a H-bond interaction with an adjacent basic amino acid residue (Arg501 of gt1b, Lys501 of gt2a) in the hydrophobic pocket of the protein, ${ }^{26}$ thus contributing to an enhanced potency. The resulting 2-alkyl-N-arylquinolones indeed exhibited an improved anti-HCV potency in genotype (gt) $2 \mathrm{~b}$ replicon. Then, further structural optimization was focused on the improvement of the drug-likeness of the lead compound through scaffold reshuffling. According to the binding mode of the 2-alkyl quinolone series with the NS5B polymerase, the solvent-exposing C-6/C-7 portion was truncated and the C-2 substituent was constrained with the C-3 moiety to deliver a brand new 1,6-naphthyridine-4,5(1H,6H)-dione scaffold, maintaining similar pharmacophores to that of quinolone 4. Preliminary SAR study was conducted to determine an optimal substitution to achieve the key interactions with the two hydrophobic pockets.
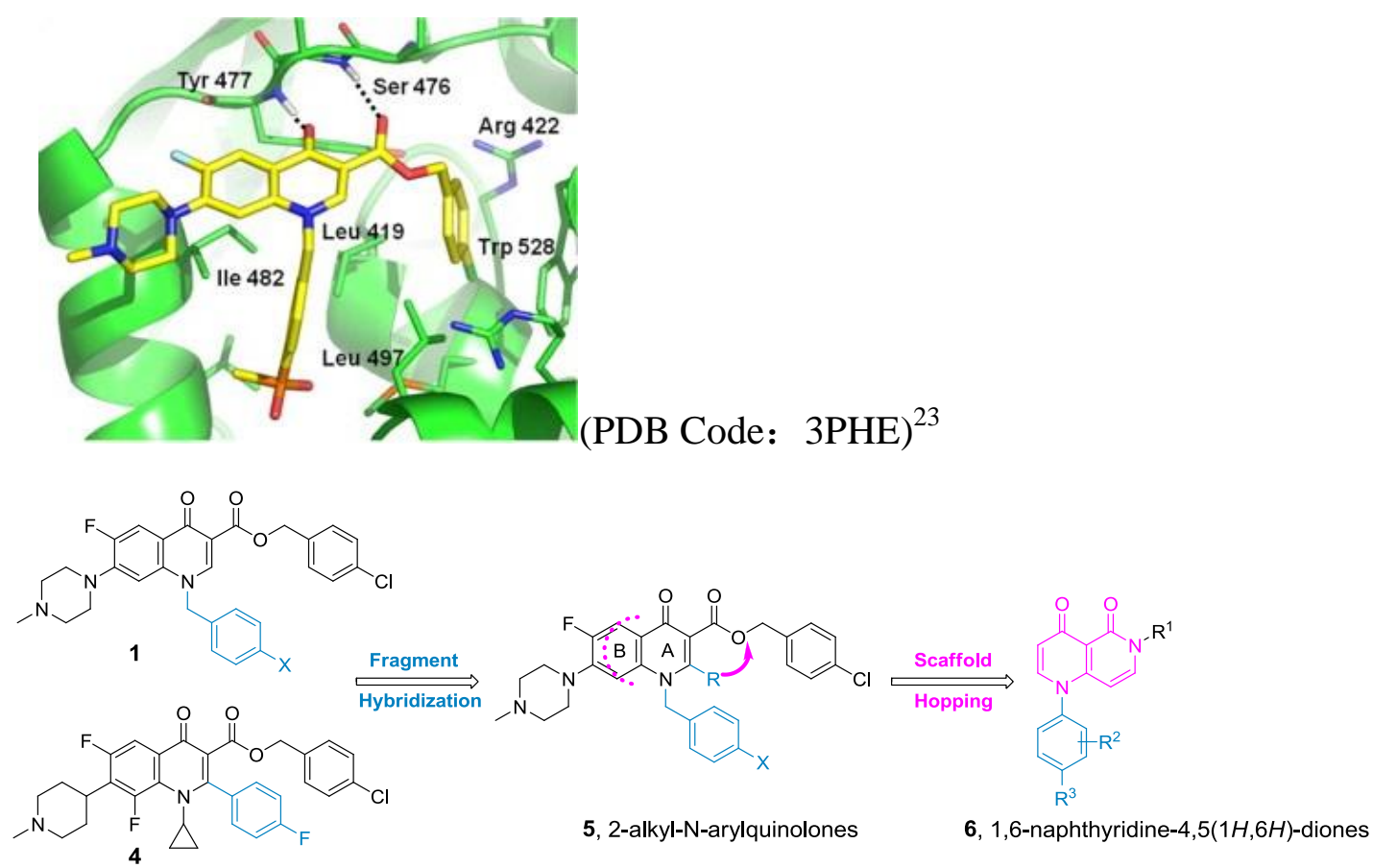

Fig 2. Structure-based design of 2-alkyl quinolone and 1,6-naphthyridine-4,5(1H,6H)-dione 
derivatives as potential HCV NS5B polymerase inhibitors.

The synthesis of 2-alkyl- $N$-arylquinolone derivatives 5a-e was described in Scheme 1. Among the quinolone series, compound $\mathbf{1}$ was prepared as a reference compound according to a reported procedure. ${ }^{23}$ The synthetic routes of the target compounds varied according to the variation on C-7 substituent (5a-c and 5d-f), which were reported to point to the solvent area and exert remarkable influence on cellular replicon potency. Starting from commercially available methyl 2-amino-4,5-difluorobenzoate, reductive amination with $p$-chlorobenzaldehyde followed by a one-pot hydrolysis and esterification gave the activated ester $\mathbf{8}$. Then, cyclization of $\mathbf{8}$ with various $\beta$-oxo esters formed the 2-alkyl quinolone scaffolds 9a-c. Hydrolysis of 9a-c under different conditions gave quinolone acids with various substitution at C-7, which was treated with $p$-cholorobenzyl chloride to furnish 5a-c and 5d-f. Notably, the C-7 amino substituent in target compounds 5d-f were introduced through $\mathrm{S}_{\mathrm{N}} \mathrm{Ar}$ reaction from the corresponding precursors $\mathbf{1 0 a}-\mathbf{b}$.

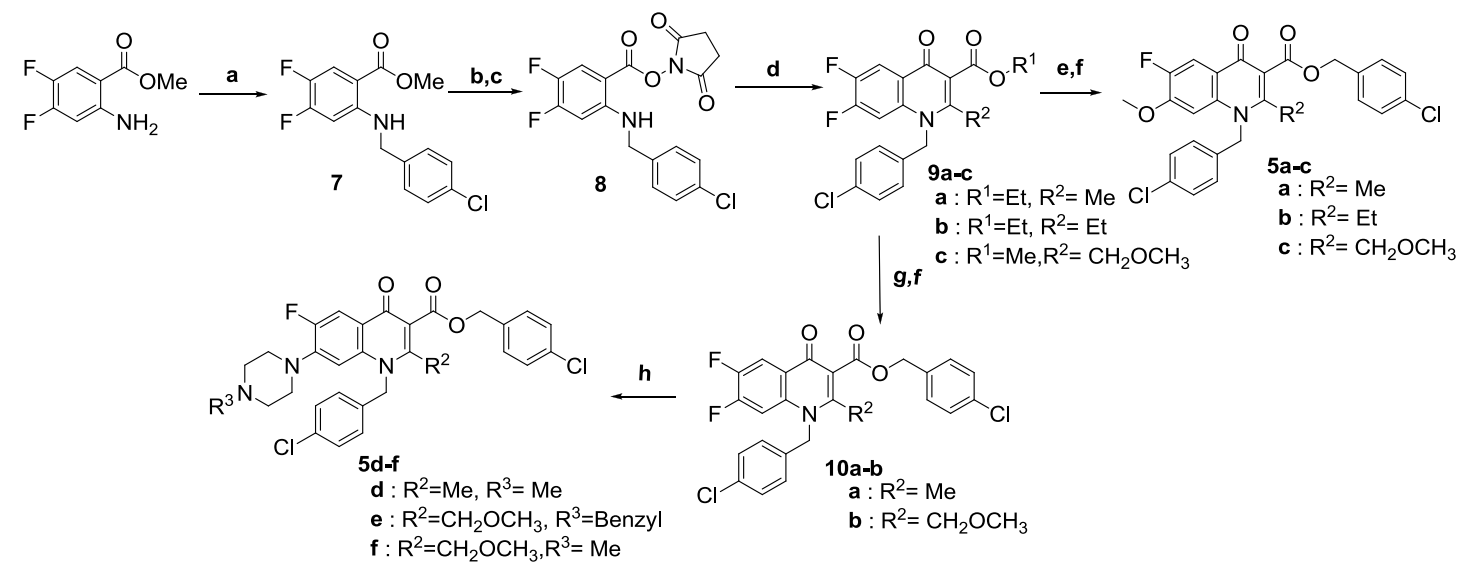

Scheme 1. Reagents and conditions: (a) p-chlorobenzyaldehyde (1.25 equiv), $\mathrm{NaBH}(\mathrm{OAc})_{3}(2.3$ eqiv), HOAc, RT, 94\%; (b) LiOH, $\mathrm{H}_{2} \mathrm{O}-\mathrm{THF}(1: 3, \mathrm{v} / \mathrm{v}), 45^{\circ} \mathrm{C}$. overnight; (c) DCC (2.0 equiv), HOSu (2.0 equiv), DCM, 95\% overall yield for two steps; (d) $\mathrm{R}^{2} \mathrm{COCH}_{2} \mathrm{CO}_{2} \mathrm{R}^{1}$ (2.2 equiv), $\mathrm{NaH}$ (2.2 equiv), toluene, $130^{\circ} \mathrm{C}, 49-74 \%$; (e) $\mathrm{NaOH}, \mathrm{MeOH}-\mathrm{THF}-\mathrm{H}_{2} \mathrm{O}(3: 2: 3, \mathrm{v} / \mathrm{v}), 90^{\circ} \mathrm{C}, 57-65 \%$ for two steps; (f) $p$-chlorobenzylchloride (3.0 equiv), $\mathrm{Cs}_{2} \mathrm{CO}_{3}$ (3.0 equiv), DMF, $60^{\circ} \mathrm{C} ; \mathrm{g}$ ) $\mathrm{KOH}$, THF- $\mathrm{H}_{2} \mathrm{O}(3: 1, \mathrm{v} / \mathrm{v}), 70^{\circ} \mathrm{C}, 67-78 \%$ for two steps; (h) $\mathrm{N}$-methylpiperazine (10.0 equiv), $\mathrm{K}_{2} \mathrm{CO}_{3}$ (3.0 equiv), DMF, $60^{\circ} \mathrm{C}, 56-74 \%$.

Scheme 2 describes the preparation of the 1,6-naphthyridine-4,5(1H,6H)-diones with hydrophobic substituents at the $N-1$ and $N-6$ positions. To the best of our knowledge, this is the first time to report the design and synthesis of 
1,6-naphthyridine-4,5(1H,6H)-diones and evaluate their biological activities. As depicted in Scheme 2, we established a convenient synthesis toward these novel scaffold compounds. A reversible Michael addition reaction of 2-methoxypyridin-4-amine with 5-(methoxymethylene)-2,2-dimethyl -1,3-dioxane-4,6-dione can readily generate $\mathbf{1 1}$ which was transformed into the naphthyridine core 12 through Friedel-Crafts reaction at high temperature. The $\mathrm{N}$-1aryl group was installed via $\mathrm{S}_{\mathrm{N}} \mathrm{Ar}$ displacement to give intermediate $\mathbf{1 3}$ where the cross coupling reactions were tried but failed. Removal of methyl group by acidolysis followed by selective alkylation of the N-6 atom delivered the target compounds (6a-c) or the $N^{I}-\left(4-\mathrm{NO}_{2}-\mathrm{Ph}\right)$ precursors, which were then reduced to produce the amino compounds (6d-m) and further transformed to furnish amides and ureas (6n-v) via condensation with acids and isocyanates, respectively.

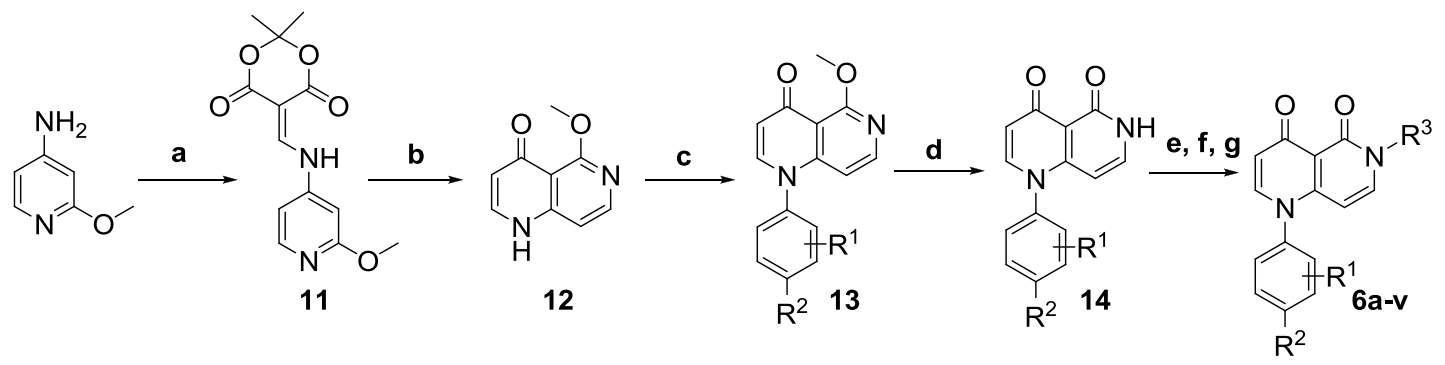

Scheme 2. Reagents and conditions: (a) 5-(methoxymethylene)-2,2-dimethyl-1,3-dioxane-4,6dione $\left(1.3\right.$ equiv) , $i-\mathrm{PrOH}, 100^{\circ} \mathrm{C}, 1 \mathrm{~h}, 65 \%$; (b) diphenyl oxide, $220^{\circ} \mathrm{C}, 60 \%$; (c) $\operatorname{ArF}$ (10.0 equiv), $\mathrm{NaH}$ (4.0 equiv), diphenyl oxide, microwave $\left(150^{\circ} \mathrm{C}, 150 \mathrm{~W}\right), 4 \mathrm{~h}, 26-80 \%$; (d) conc. $\mathrm{HCl}, 90^{\circ} \mathrm{C}, 1 \mathrm{~h}$ (quantitative); (e) $\mathrm{R}^{3} \mathrm{Cl}$ or $\mathrm{R}^{3} \mathrm{Br}$ (3.5 equiv), TBAF (10.0 equiv), THF, rt, overnight; (f) $\mathrm{Zn}, \mathrm{HOAc}$, rt, 1h, 65-87\%; (g) $\mathrm{R}^{4} \mathrm{COOH}$ (4.0 equiv), HATU (5.0 equiv), DIEA (10.0 equiv), DCM, RT, overnight or $\mathrm{R}^{4} \mathrm{NCO}$ ( 1.5 equiv), DCM, $40^{\circ} \mathrm{C}$.

All the compounds were evaluated in vitro with their antiviral potency and cytotoxicity in Huh7.5.1 replicon 2a system. The antiviral activities of 2-substituted quinolone derivatives were shown in Table 1. Although the reference compound 1 was reported to show potent antiviral activity against genotype 1 virus $\left(\mathrm{EC}_{50}(\mathrm{gt} 1 \mathrm{a})=0.41\right.$ $\left.\mu \mathrm{M}, \mathrm{EC}_{50}(\mathrm{gt} 1 \mathrm{~b})=0.12 \mu \mathrm{M}\right),{ }^{23}$ as other NS5B thumb II inhibitors functioned ${ }^{27}$, it just displayed moderate replication inhibition against $\mathrm{HCV}$ genotype $2 \mathrm{a}\left(\mathrm{EC}_{50}=4.3 \mu \mathrm{M}\right)$ in our assay. Gratifyingly, the incorporation of a small and flexible alkyl group at C-2 position of the quinolone in the presence of $\mathrm{N}-1$ aryl substitution indeed exerted an 
enhancing effect in the cellular replicon potency (5a, $\mathbf{5 f}$ vs $\mathbf{1})$. As we anticipated, the steric hindrance of $\mathrm{C} 2$-substituent would interfere with the interaction of the bulky $N^{1}$-substituent with the hydrophobic pocket, thus compound 5a-c showed reduced potency with increasing steric hindrance at C-2 ( $\left.-\mathrm{Me}>-\mathrm{Et}>-\mathrm{CH}_{2} \mathrm{OCH}_{3}\right)$. However, When the privileged fragment of (4-methyl) morpholinyl group was installed in C-7 position, the introduction of methoxylmethyl $\left(\mathrm{CH}_{3} \mathrm{OCH}_{2}-\right)$ group at 2-position resulted in a substantial improvement of the antiviral activity $\left(\mathbf{5 f}, \mathrm{EC}_{50}=0.4 \mu \mathrm{M}\right)$, by a factor of 11-fold relative to the reference compound 1. Even compared to our originally identified 2-arylquinolone inhibitor $4,{ }^{22}$ the optimal combination of the two hydrophobic substituents at position $\mathrm{N}-1$ and $\mathrm{C}-2$ (5f vs 4) conferred superior anti-HCV potency and selectivity index, which was consistent well with our initial rational design.

Table $1 \mathrm{R}^{1}$ and $\mathrm{R}^{2} \mathrm{SAR}$ of 2-alkyl quinolones

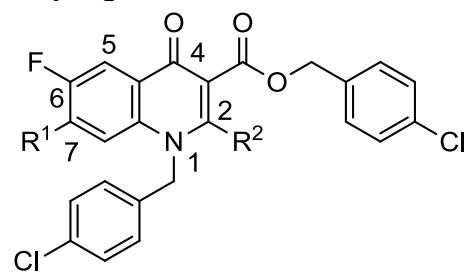

1, 5a-f

\begin{tabular}{|c|c|c|c|c|c|}
\hline \multirow[b]{2}{*}{ Compd. } & \multicolumn{2}{|l|}{ Structure } & \multirow{2}{*}{$\begin{array}{l}\text { HCV-flu(gt2a) } \\
\text { EC }_{50}(\mu \mathrm{M})\end{array}$} & \multirow{2}{*}{$\begin{array}{l}\text { MTT assay } \\
\mathrm{CC}_{50}(\mu \mathrm{M})\end{array}$} & \multirow[b]{2}{*}{$\mathrm{SI}^{*}$} \\
\hline & $\mathrm{R}^{1}$ & $\mathrm{R}^{2}$ & & & \\
\hline 1 & (4-methyl)morpholinyl & $\mathrm{H}$ & 4.3 & $>40$ & $>9.3$ \\
\hline $5 \mathbf{a}$ & $\mathrm{OMe}$ & $\mathrm{Me}$ & 2.4 & $>40$ & $>16.7$ \\
\hline $5 b$ & $\mathrm{OMe}$ & Et & 3.7 & 26.8 & 7.2 \\
\hline $5 c$ & $\mathrm{OMe}$ & $\mathrm{CH}_{2} \mathrm{OCH}_{3}$ & 11.1 & $>40$ & $>3.6$ \\
\hline $5 d$ & (4-methyl)morpholinyl & $\mathrm{Me}$ & 7.2 & 33.1 & 4.6 \\
\hline $5 e$ & (4-benzyl)morpholinyl & $\mathrm{CH}_{2} \mathrm{OCH}_{3}$ & 4.9 & $>40$ & 8.2 \\
\hline $5 f$ & (4-methyl)morpholinyl & $\mathrm{CH}_{2} \mathrm{OCH}_{3}$ & 0.4 & 4.3 & 10.8 \\
\hline $4^{22}$ & & & 2.02 & 13.2 & 5.5 \\
\hline
\end{tabular}

${ }^{*}$ SI: selective index, $\mathrm{SI}=\mathrm{CC}_{50} / \mathrm{EC}_{50}$.

Considering the relatively poor physicochemical property of the quinolone 
structures ${ }^{24}$ further structural optimization was directed to evolve drug-like inhibitors through scaffold hopping. Based on the co-crystal structure of the quinolone 2 with the NS5B protein, the solvent exposing portion with $\mathrm{C}-6 / \mathrm{C}-7$ substituents had no direct contact with the enzyme, though this moiety was beneficial for the replicon potency. On the other hand, the 2-substituent was involved in the hydrophobic interaction with the protein as well. Taken together, a new scaffold of 1,6-naphthyridine-4,5-dione resulted from the B-ring truncation and the cyclization of the C-2 substituent with C-3 moiety of the quinolone core (Fig 2). A global SAR study on $N^{1}$ - and $N^{6}$-substituent was explored to determine an optimal substitution pattern for this new scaffold. First of all, the $\mathrm{N}^{6}-(4-$ chlorobenzyl) group was fixed to mimic the C3-benzyl group of quinolone $\mathbf{1}$, an exploration of $\mathrm{R}^{1}$ and $\mathrm{R}^{2}$ on $\mathrm{N}-1$ phenyl ring was conducted. As shown in Table 2, most of the $N^{1}$-phenyl- $N^{6}$-(4-chlorobenzyl)-1,6-naphthyridine-4,5-diones (6a-h) exhibited moderate to high inhibition rate on $\mathrm{HCV}$ replication and low cytotoxicity, except for the 4'-cyano substituted analog $(\mathbf{6 c})$. Compared to the amino or nitro group at 4'-position, the less polar nature of cyano group might account for the activity loss. On the other hand, a hydrophobic substituent at 2'-position and/or 3'-position of $N^{1}$-aryl group was beneficial for the antiviral activity with 3 '-substitution being superior to the 2'-position. The antiviral activity order as $-\mathrm{CF}_{3}>-\mathrm{Cl}>-\mathrm{H}$ for 3'-substitution (6f, $\mathrm{EC}_{50}$ not identified; $6 \mathbf{g}, \mathrm{EC}_{50}=6.5 \mu \mathrm{M} ; \mathbf{6} \mathbf{h},{ }^{28} \mathrm{EC}_{50}=2.5 \mu \mathrm{M}$; Table 2) indicated a hydrophobic and bulky group at this position might confer a better interaction with the protein by occupying a small hydrophobic pocket mainly defined by Leu419, Met423, and Val485. The substituent at 4'-position

Although $p$-chlorobenzyl group was recognized as a privileged fragment for C-3 position of the quinolone, the N-6 substituent was investigated as well on the new naphthyridinedione core. Aromatic and aliphatic groups with different ring size were examined (Table 2, 6h-m). Unfortunately, replacement with either an unsubstituted benzyl group or aliphatic ring led to a complete loss in activities (6k-m), probably due to the impaired $\pi-\pi$ stacking interaction with Trp528. Correspondingly, hydrophobic substituent on the phenyl ring facilitated the antiviral potency $(\mathbf{6} \mathbf{h}-\mathbf{j})$ with the chloro 
being the best.

Further effort to improve the activity of the 1,6-naphthyridine-4,5-dione chemotype was switched to the derivatization on the $\mathrm{N}^{1}$-phenyl ring. Since a sulfone oxygen of compound $\mathbf{2}$ anchored the enzyme by forming a key H-bond interaction with backbone amide hydrogen of Leu497 and the 4'- $\mathrm{NH}_{2}$ moiety on $\mathrm{N}^{1}$-phenyl ring was expected to reside the same region, we designed 4'-amide and 4'-urea derivatives (6n-v, Table 2). We assume that the incorporation of the carbonyl oxygen as HBA and an additional aromatic fragment could extend the hydrophobic interaction with the binding pocket. However, we failed to install an amide or urea substituent at $4^{\prime}-\mathrm{NH}_{2}$ in the favorable $N^{1}-\left(3^{\prime}-\mathrm{CF}_{3}-4^{\prime}-\mathrm{NH}_{2}\right)$ phenyl substituted template, so we tested our idea on 2'-sbustituted and nonsubstituted chemotypes. Disappointingly, the introduction of the arylcarboxamido or arylcarbonyldiimino moiety didn't exert remarkable enhancing effect. Some of the resulting $N^{1}$-(4'-benzamido)phenyl-1,6-naphthyridine-4,5-dione derivatives exhibited low micromolar replicon potency $\left(\mathbf{6 o}, \mathrm{EC}_{50}=4.6 \mu \mathrm{M} ; \mathbf{6 u}, \mathrm{EC}_{50}=1.4 \mu \mathrm{M}\right)$, but with a compromised safety window. As a result, 1-(4-amino-3-(trifluoromethyl)phenyl)-6-(4-chlorobenzyl)-1,6-naphthyridine-4,5(1H, $6 \mathrm{H}$ )-dione $\mathbf{6 h}^{29}$ showed the best biological profile $\left(\mathrm{EC}_{50}\right.$ (replicon, gt2a) $=2.5 \mu \mathrm{M}$; $\left.\mathrm{CC}_{50}=17.9 \mu \mathrm{M}\right)$ in this series. The biological results suggest that the brand new structure 1,6-naphthyridine-4,5(1H, 6H)-dione could serve as promising new $\mathrm{HCV}$ inhibitors for further development.

Table 2. Global SAR exploration of 1,6-naphthyridine-4,5-dione analogs as HCV inhibitors

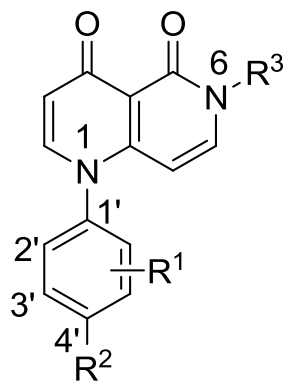

\begin{tabular}{lllll} 
Compd. & Structure & HCV-flu (gt2a) & MTT assay & SI $^{\mathrm{b}}$ \\
\hline
\end{tabular}




\begin{tabular}{|c|c|c|c|c|c|c|c|c|}
\hline & $\mathrm{R}^{1}$ & $\mathrm{R}^{2}$ & $\mathrm{R}^{3}$ & $\begin{array}{c}\text { Inhibition } \\
\text { Rate (\%), } \\
@ 5 \mu \mathrm{M}\end{array}$ & $\begin{array}{l}\mathrm{EC}_{50} \\
(\mu \mathrm{M})\end{array}$ & $\begin{array}{c}\text { Cell } \\
\text { viability } \\
(\%), @ 5 \\
\mu \mathrm{M} \\
\end{array}$ & $\begin{array}{l}\mathrm{CC}_{50} \\
(\mu \mathrm{M})\end{array}$ & \\
\hline $6 a$ & $2^{\prime}-\mathrm{CF}_{3}$ & $\mathrm{NO}_{2}$ & & 58.6 & - & 88.2 & - & - \\
\hline $6 b$ & $3^{\prime}-\mathrm{CF}_{3}$ & $\mathrm{NO}_{2}$ & & 65.7 & 4.8 & 75.6 & 10.6 & 2.2 \\
\hline $6 c$ & $3^{\prime}-\mathrm{CF}_{3}$ & $\mathrm{CN}$ & & n.i. $^{\mathrm{a}}$ & - & 86.4 & - & - \\
\hline $6 d$ & $2^{\prime}-\mathrm{CF}_{3}$ & $\mathrm{NH}_{2}$ & & 43.8 & - & 84.8 & - & - \\
\hline $6 e$ & $2^{\prime}-\mathrm{CH}_{3}$ & $\mathrm{NH}_{2}$ & & 52.0 & - & 91.6 & - & - \\
\hline $6 f$ & $\mathrm{H}$ & $\mathrm{NH}_{2}$ & & 39.8 & - & 94.6 & - & - \\
\hline $6 \mathrm{~g}$ & $3^{\prime}-\mathrm{Cl}$ & $\mathrm{NH}_{2}$ & & 68.0 & 6.4 & 79.2 & 19.4 & 3.0 \\
\hline $6 \mathrm{~h}$ & $3^{\prime}-\mathrm{CF}_{3}$ & $\mathrm{NH}_{2}$ & & 78.9 & 2.5 & 74.3 & 17.9 & 7.2 \\
\hline $6 \mathbf{i}$ & & & & 38.7 & - & 100.0 & - & - \\
\hline $6 \mathbf{j}$ & & & & 51.7 & - & 99.8 & - & - \\
\hline $6 k$ & $3^{\prime}-\mathrm{CF}_{3}$ & $\mathrm{NH}_{2}$ & & n.i. ${ }^{a}$ & - & 96.8 & - & - \\
\hline 61 & & & & 7.7 & - & 100.0 & - & - \\
\hline $6 m$ & & & & n.i. ${ }^{a}$ & - & 100.0 & - & - \\
\hline $6 n$ & $\mathrm{H}$ & & & 41.7 & - & 88.7 & - & \\
\hline 60 & $\mathrm{H}$ & & & 95.7 & 4.6 & 46.1 & 6.4 & 1.4 \\
\hline $6 p$ & $\mathrm{H}$ & & & 52.3 & - & 68.6 & - & \\
\hline $6 q$ & $\mathrm{H}$ & & & 42.6 & - & 88.0 & - & \\
\hline $6 r$ & $\mathrm{H}$ & & & 18.8 & - & 98.4 & - & \\
\hline $6 s$ & $2^{\prime}-\mathrm{CH}_{3}$ & & & 55.2 & - & 72.6 & - & \\
\hline $6 t$ & $2^{\prime}-\mathrm{CH}_{3}$ & & & 53.1 & - & 70.4 & - & \\
\hline $6 u$ & 2'- $-\mathrm{CF}_{3}$ & & & 98.2 & 1.4 & 38.4 & 1.5 & 1.1 \\
\hline $6 v$ & $2^{\prime}-\mathrm{CF}_{3}$ & & & 33.4 & - & 75.4 & - & \\
\hline
\end{tabular}

${ }^{a}$ n.i.: no inhibition was observed at the concentration tested. ${ }^{b}$ SI: selective index, $\mathrm{SI}=$ $\mathrm{CC}_{50} / \mathrm{EC}_{50}$. 
In order to throw light on the molecular mechanism of our designed inhibitors, we performed molecular modeling to propose the binding mode of the most potent quinolone inhibitor $\mathbf{5 f}$ and the 1,6-naphthyridine -4,5(1H,6H)-dione inhibitor $\mathbf{6 h}$ based on the X-ray co-crystal structure of TSII inhibitor 2 with NS5B polymerase (PDB: 3PHE). ${ }^{23,30}$ For compound $\mathbf{5 f}$, the docking result described a similar binding mode as that of 2 (Figure 3). Although the distance between the two heavy atoms (O $\left(\mathrm{CH}_{2} \mathrm{OCH}_{3}\right)$ of quinolone $\mathbf{5 f}$ and $\mathrm{N}$ in $\mathrm{Arg} 501$ of $\left.\mathrm{NS} 5 \mathrm{~B}\right)$ was measured as $4.1 \AA$, we assumed an $\mathrm{H}$-bond interaction might take place through a water bridge in physiological environment, to which the significant gain in the antiviral activity of $\mathbf{5 f}$ was attributed.

The docking results of compound $6 \mathbf{h}$ (Fig. 4A-C) predicted a similar binding mode that the two carbonyl groups of the naphthyridinedione nucleus anchored the protein through hydrogen bonding to backbone amide NHs of Tyr477 and Ser476, respectively. The N-6 benzyl group occupied a deep hydrophobic pocket and formed $\pi-\pi$ stacking interaction with Trp528, the $\mathrm{N}-1$ aryl group stretched into another long shallow hydrophobic channel defined by Leu419, Ala486, Leu489, Pro496 and Leu497. Furthermore, the trifluoromethyl group headed into a small pocket locating at the bottom as originally expected and the fluorine atom formed a H-bond interaction with the backbone amide NH of Leu497 since the distance between (N)H-F was $2.3 \AA$ (Fig 4A, 4C). Overlaying the docking results with the quinolone 2 exhibited an excellent superimposition (Fig 4B). Compound $6 \mathbf{h}$ shared almost all the pharmacophores with other reported thumb site II inhibitors. The inconsistence of the relatively reduced cellular potency of this series might be due to the cell membrane permeability factors of the compounds. Structurally diverse analogs of the naphthyridinedione were under construction and assay. 


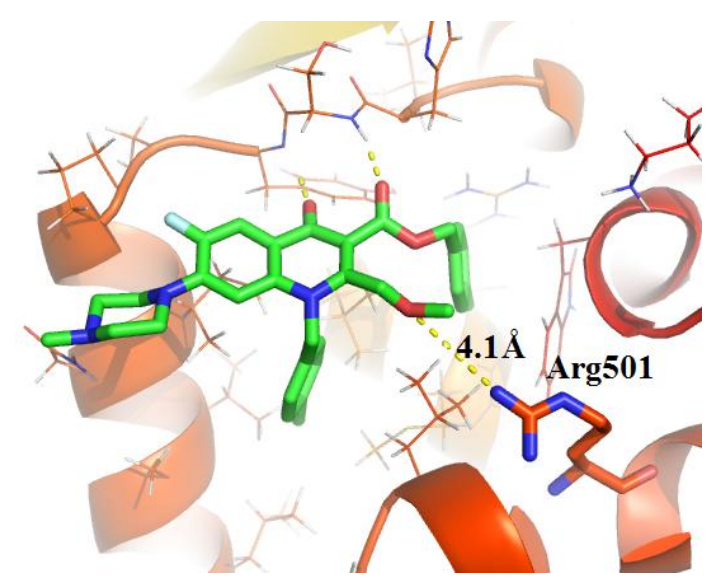

Fig 3. Proposed binding mode of selected 2-alkyl quinolone $\mathbf{5 f}$ based on co-crystal structure of $\mathbf{2}$ bound to NS5B polymerase thumb pocket II.
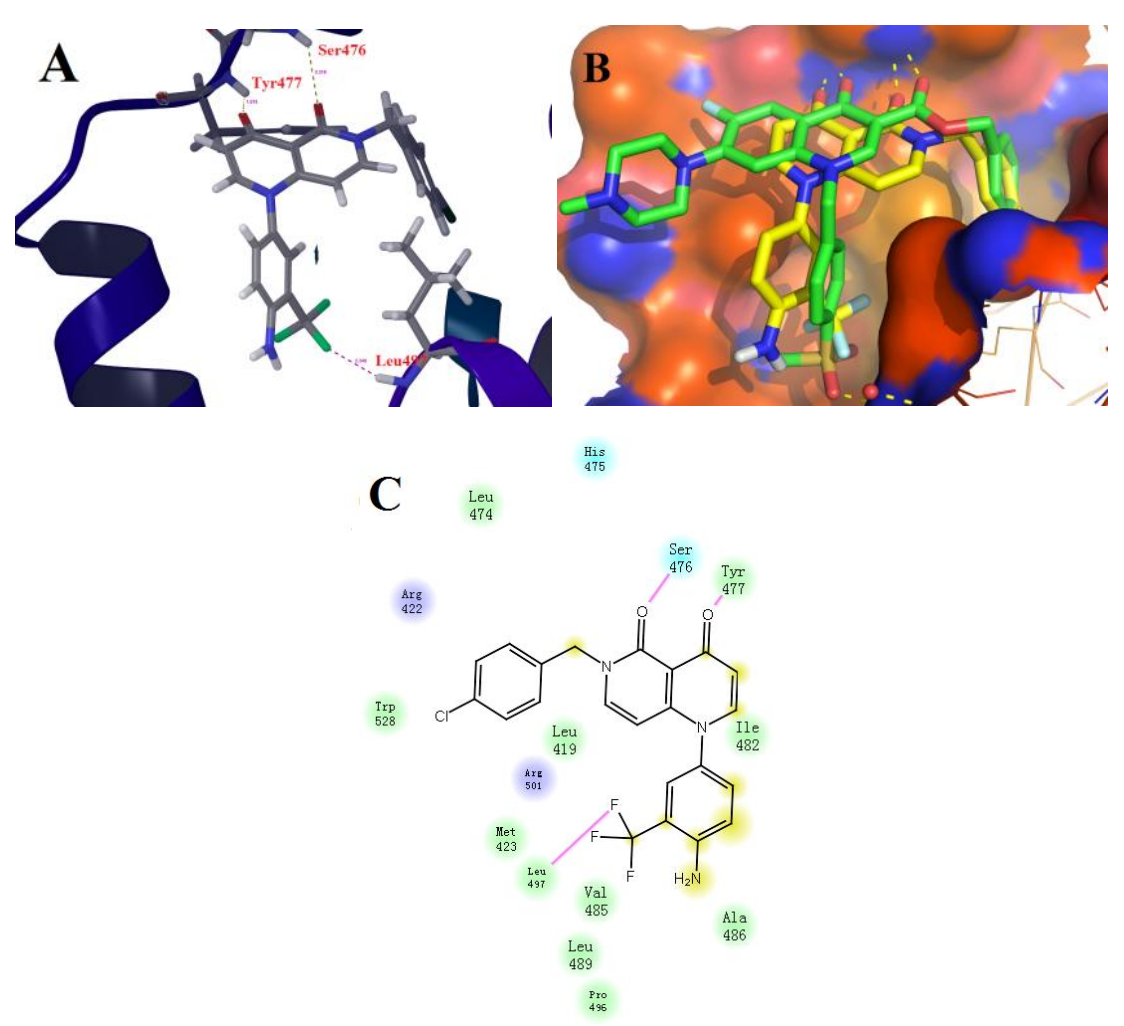

Fig 4. (A) The modeling of compound $\mathbf{6 h}$ bound to NS5B based on the cocrystal structure of 2 with NS5B (PDB:3PHE). (B) superimposition of compound $\mathbf{6} \mathbf{h}$ to the crystal structure of compound 2. (C) ligand-enzyme interactions of compound $\mathbf{6 h}$.

In conclusion, we conducted a further structural optimization of 2-substituted quinolones based on the binding mode with NS5B polymerase. A molecular hybridization of 2-aryl quinolones and the reported inhibitor $\mathbf{1}$ lead to a new class of C2-alkyl-N1-aryl quinolones with more than 10-fold improvement in the antiviral activity. Further drug-like structural optimization on 2-alkyl quinolones led to the 
identification of a brand new class of naphthyridinediones as HCV inhibitors by using scaffold hopping strategy. Global SAR exploration furnished the most potent compound with low micromolar antiviral activity. The molecular modeling study interpreted the binding modes of the 2-alkyl quinolones and 1,6-naphthyridine-4,5(1H,6H)-dione analogs as NS5B thumb pocket II binders.

\section{Acknowledgments}

We are grateful to Ms. Jing Xing at Drug Design and Discovery Centre (DDDC), Shanghai Institute of Materia Medica for her generous help in molecular modeling of compound $\mathbf{5 f}$ and $\mathbf{6 h}$. This work was supported by grants from National Science Foundation of China (81325020, 81361120410, 81321092).

\section{References and Notes}

1. Bosetti, C.; Levi, F.; Lucchini, F.; Zatonski, W. A.; Negri, E.; La Vecchia, C. Journal of hepatology 2007, 46, 827.

2. Lavanchy, D. Clin Microbiol Infec 2011, 17, 107.

3. Lozano, R.; Naghavi, M.; Foreman, K.; Lim, S.; Shibuya, K.; Aboyans, V.; Abraham, J.; Adair, T.; Aggarwal, R.; Ahn, S. Y., et al. Lancet 2012, 380, 2095.

4. Neukam, K.; Macias, J.; Mira, J. A.; Pineda, J. A. Expert opinion on pharmacotherapy 2009, 10, 417.

5. Ghany, M. G.; Strader, D. B.; Thomas, D. L.; Seeff, L. B. Hepatology 2009, 49, 1335.

6. De Clercq, E. Biochemical pharmacology 2014, 89, 441.

7. Lin, K.; Perni, R. B.; Kwong, A. D.; Lin, C. Antimicrobial agents and chemotherapy 2006, 50, 1813.

8. Venkatraman, S.; Bogen, S. L.; Arasappan, A.; Bennett, F.; Chen, K.; Jao, E.; Liu, Y. T.; Lovey, R.; Hendrata, S.; Huang, Y. H., et al. Journal of medicinal chemistry 2006, 49, 6074.

9. Cannalire, R.; Barreca, M. L.; Manfroni, G.; Cecchetti, V. Journal of medicinal chemistry 2016, 59,16 .

10. Sofia, M. J.; Chang, W.; Furman, P. A.; Mosley, R. T.; Ross, B. S. J. Med. Chem. 2012, 55, 2481.

11. Gane, E. J.; Stedman, C. A.; Hyland, R. H.; Ding, X.; Svarovskaia, E.; Symonds, W. T.; Hindes, R.

G.; Berrey, M. M. The New England journal of medicine 2013, 368, 34.

12. Ivan Gentile, A. R. B., ; Guglielmo Borgia. Reviews on Recent Clinical Trials 2014, 9, 115.

13. Link, J. O.; Taylor, J. G.; Xu, L.; Mitchell, M.; Guo, H.; Liu, H.; Kato, D.; Kirschberg, T.; Sun, J.; Squires, N., et al. Journal of medicinal chemistry 2014, 57, 2033.

14. DeGoey, D. A.; Randolph, J. T.; Liu, D.; Pratt, J.; Hutchins, C.; Donner, P.; Krueger, A. C.; Matulenko, M.; Patel, S.; Motter, C. E., et al. Journal of medicinal chemistry 2014, 57, 2047.

15. Poordad, F.; Lawitz, E.; Kowdley, K. V.; Cohen, D. E.; Podsadecki, T.; Siggelkow, S.; Heckaman, M.; Larsen, L.; Menon, R.; Koev, G., et al. N. Engl. J. Med. 2013, 368, 45. 
16. Behrens, S. E.; Tomei, L.; DeFrancesco, R. Embo Journal 1996, 15, 12.

17. Lesburg, C. A.; Cable, M. B.; Ferrari, E.; Hong, Z.; Mannarino, A. F.; Weber, P. C. Nat Struct Biol 1999, 6, 937.

18. Barreca, M. L.; Iraci, N.; Manfroni, G.; Cecchetti, V. Future Medicinal Chemistry 2011, 3, 1027.

19. Lin, J. P.; Long, Y. Q. Chemical communications 2013, 49, 5313.

20. Hu, W.; Lin, J. P.; Song, L. R.; Long, Y. Q. Org Lett 2015, 17, 1268.

21. Zhi, Y.; Gao, L. X.; Jin, Y.; Tang, C. L.; Li, J. Y.; Li, J.; Long, Y. Q. Bioorgan Med Chem 2014, 22, 3670 .

22. Wang, S. F.; Lin, J. P.; He, P. L.; Zuo, J. P.; Long, Y. Q. Acta Chim Sinica 2014, 72, 906.

23. Kumar, D. V.; Rai, R.; Brameld, K. A.; Somoza, J. R.; Rajagopalan, R.; Janc, J. W.; Xia, Y. M.; Ton, T. L.; Shaghafi, M. B.; Hu, H., et al. Bioorganic \& medicinal chemistry letters 2011, $21,82$.

24. Kumar, D. V.; Rai, R.; Brameld, K. A.; Riggs, J.; Somoza, J. R.; Rajagopalan, R.; Janc, J. W.; Xia, Y. M.; Ton, T. L.; Hu, H., et al. Bioorganic \& medicinal chemistry letters 2012, 22, 300.

25. Manfroni, G.; Cannalire, R.; Barreca, M. L.; Kaushik-Basu, N.; Leyssen, P.; Winquist, J.; Iraci, N.; Manvar, D.; Paeshuyse, J.; Guhamazumder, R., et al. Journal of medicinal chemistry 2014, 57, 1952.

26. Biswal, B. K.; Cherney, M. M.; Wang, M.; Chan, L.; Yannopoulos, C. G.; Bilimoria, D.; Nicolas, O.; Bedard, J.; James, M. N. J. Biol. Chem. 2005, 280, 18202.

27. Eltahla, A. A.; Tay, E.; Douglas, M. W.; White, P. A. Antimicrobial agents and chemotherapy 2014, 58,7215 .

28. The characterization data of compound 5f: m.p. $142-144^{\circ} \mathrm{C}, 1 \mathrm{H}$ NMR (300 MHz, Methanol-d4) $\delta$ $7.78(\mathrm{~d}, \mathrm{~J}=13.2 \mathrm{~Hz}, 1 \mathrm{H}), 7.51(\mathrm{~d}, \mathrm{~J}=8.7 \mathrm{~Hz}, 2 \mathrm{H}), 7.36(\mathrm{dd}, \mathrm{J}=12.3,8.6 \mathrm{~Hz}, 4 \mathrm{H}), 7.09$ (d, J = 8.3 Hz, $2 \mathrm{H}), 6.76(\mathrm{~d}, \mathrm{~J}=7.2 \mathrm{~Hz}, 1 \mathrm{H}), 5.60(\mathrm{~s}, 2 \mathrm{H}), 5.37$ (s, 2H), $4.47(\mathrm{~s}, 2 \mathrm{H}), 3.20(\mathrm{~s}, 3 \mathrm{H}), 3.15-2.77(\mathrm{~m}, 4 \mathrm{H})$, $2.76-2.35$ (m, 4H), 2.31 (s, 3H). 13C NMR (126 MHz, DMSO) $\delta 172.05,166.19,153.01,151.04$, $146.81,144.07,138.02,135.73,134.94,132.71,131.88,130.12,128.79,128.40,127.76,120.09$, $117.95,110.67,110.39,109.73,106.92,68.61,65.70,58.04,53.97,49.27,45.57$. MS (ESI) m/z 598.2 $(\mathrm{M}+\mathrm{H})^{+}$.

29. The characterization data of copound $6 \mathbf{h}$ : m.p. $184-186^{\circ} \mathrm{C}, 1 \mathrm{H}$ NMR (400 MHz, DMSO-d6) $\delta$ $7.80(\mathrm{~d}, \mathrm{~J}=7.8 \mathrm{~Hz}, 1 \mathrm{H}), 7.61(\mathrm{~d}, \mathrm{~J}=7.8 \mathrm{~Hz}, 1 \mathrm{H}), 7.51(\mathrm{~d}, \mathrm{~J}=2.3 \mathrm{~Hz}, 1 \mathrm{H}), 7.40(\mathrm{~d}, \mathrm{~J}=8.5 \mathrm{~Hz}, 2 \mathrm{H})$, $7.38(\mathrm{dd}, \mathrm{J}=8.8,2.3 \mathrm{~Hz}, 1 \mathrm{H}), 7.31(\mathrm{~d}, \mathrm{~J}=8.5 \mathrm{~Hz}, 2 \mathrm{H}), 6.96(\mathrm{~d}, \mathrm{~J}=8.8 \mathrm{~Hz}, 1 \mathrm{H}), 6.12(\mathrm{~s}, 2 \mathrm{H}), 6.03$ (d, J $=7.8 \mathrm{~Hz}, 1 \mathrm{H}), 5.62(\mathrm{~d}, \mathrm{~J}=7.8 \mathrm{~Hz}, 1 \mathrm{H}), 5.02(\mathrm{~s}, 2 \mathrm{H}) .13 \mathrm{C}$ NMR $(126 \mathrm{MHz}, \mathrm{DMSO}) \delta 175.69,158.61$, $151.15,147.07,142.13,140.47,136.34,132.14,129.63,128.40,127.98,125.38,123.22,117.73$, 116.46, 112.94, 110.58, 110.34, 96.18, 50.10. MS (ESI) m/z 446.3 (M+H) ${ }^{+}, 468.3(\mathrm{M}+\mathrm{Na})^{+}$.

30. The docking experiments were performed with Glide 9.2 